Dal Reads

\section{The Evolution of a}

University-based

Unity Reading

Program

\section{Marlo MacKay}

Marlo MacKay is Communications Coordinator, Dalhousie University Libraries

Correspondence to this column should be addressed to Laurel Tarulli, Dalhousie University, School of Information Management, Halifax, Nova Scotia; email: laureltarulli@yahoo.com.
Readers' advisory services in academic libraries play a small but important role in building the community of readers. Campus-wide reading programs offer a great opportunity to expand readers' advisory services in the academic world. Here, Marlo MacKay, communications coordinator at Dalhousie University Libraries looks at the ups and downs of a campus reads program at her university, offering suggestions on developing and maintaining a successful event.—Editor

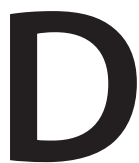

al Reads started in the summer of July 2009 as a unity reading (or community reading), initiative at Dalhousie University. The program was launched by Dr. Bonnie Neuman, then vice-president of Student Services, and Dr. Patricia DeMéo, then director of Student Academic Success Services.

The basic concept behind all unity reading programs is to provide a book club type experience to a very large group, be it a community, a city, or even a province. In the case of Dal Reads, the goal is to get as many students, faculty, and staff of Dalhousie University as possible to read the selected book and talk about it. The shared reading experience provides new students with something in common, provides a starting point for discussions, and in some cases provides themes or ideas from the book that can be woven into the curriculum in creative ways.

In that first year, the selected title was Lawrence Hill's The Book of Negroes (published in the United States under the title Someone Knows My Name). How the book was chosen in the first year is unknown, but it was a popular choice because it is a beloved title, set in Nova Scotia, exploring Black Canadian history, and one of the all-time best-selling books in Canada. A reading with the author was scheduled, and the auditorium was filled to capacity. Lawrence Hill is an author who generates excitement and crowds.

We don't have a record of what happened past October 2009 , as there are no blog posts that chronicle activities after this time. We do know that for the second year of Dal Reads, the program chose The Book of Negroes as the selected title again. Another author reading was scheduled, which was also well attended, but it's hard to say how many of the attendees were taking part in Dal Reads and how many were there just to see Lawrence Hill. It appears that there wasn't a Dal Reads program in 2011. 


\section{PARTNERING WITH ANOTHER UNITY READING PROGRAM}

In 2012, Student Services agreed to partner with One Book Nova Scotia for Dal Reads, as they had found it difficult to maintain momentum in terms of picking a book, creating events, and generating interest in the program. One Book Nova Scotia was launched in 2012 by Libraries Nova Scotia, a partnership of public and post-secondary libraries and the Nova Scotia Provincial Library, to encourage Nova Scotians to "Read the same book. Share the same story" (http://lbns .ca). It was designed to work in much the same way that other "one city, one book" unity reading programs work.

By partnering with One Book Nova Scotia, a lot of the work was already done for Dal Reads-One Book Nova Scotia selected a book, created promotional materials, and booked an author tour. Unfortunately, partnering with One Book Nova Scotia posed some challenges which became obvious once put into practice.

The biggest challenge was the pre-established timeline of One Book Nova Scotia. One Book Nova Scotia had plans to launch the program and announce the title at the same time in the hopes of generating some excitement around what the title would be. The launch date was set for a few weeks into September, but this meant that university students wouldn't get to know the title until then. Unfortunately, not many university students have time to do recreational reading mid-way through September. The original Dal Reads timeline had been designed so that the book title was announced in the summer so students could read it then, when their course load was low to none. The later timing also negated the benefit of having a shared reading experience to use as an "ice-breaker" for first-year students striking up conversations with fellow students during the first few days of term.

In addition to trying to work with a timeline that didn't fit with the schedule of the typical university student, there was also concern that students wouldn't feel engaged by a book that was preselected by a group outside of the university with no input from students. How would this book resonate with them, and why would they read it? Turnout at the reading with the author was relatively low.

In 2013 Dal Reads again partnered with One Book Nova Scotia. Turnout at this author reading was even lower, and it was determined that in order for the program to continue, something would have to change. That was when the Dalhousie Libraries truly got involved. Student Services agreed to provide some funding to assist with the continuation of the program, as well as share the artwork and branding that they had developed.

\section{DEVELOPING GUIDELINES}

The first step the Dal Libraries took was striking a committee. As the communications coordinator for the Dalhousie Libraries, I had been asked to manage the program by the university librarian Donna Bourne-Tyson. I put a call out to other Dalhousie Libraries staff members and heard from two librarians who were interested in being on the committee. To round out the team and to provide ample representation from the students' perspective, I engaged the assistance of students in Dalhousie's Master of Library and Information Studies program, seeing a natural fit between future librarians and their participation in a university-wide unity reading program.

In January 2014, the team met and started by developing objectives for the program, which included the following:

- Establish a presence and awareness of the program

- Encourage reading for pleasure

- Provide an opportunity for connection (students, faculty, staff, undergrads, and grads, regardless of area of study)

- Provide a unique activity and another option for socialization at Dalhousie

- Make reading a more social activity (as opposed to something one does alone)

- Provide an opportunity for the Dalhousie Libraries to promote the collection in a new way

- Connect with the curriculum and other university activities and interests

- Provide an opportunity for the Dalhousie Libraries and the School of Information Management (SIM) to work together

- Provide an opportunity for library school students to apply concepts around readers' advisory, appeals, etc.

After the objectives were settled, the team then established criteria for title selection. Certain aspects of the selection criteria were discussed at length, like the importance of selecting a title available in accessible formats. Students recognized the importance of having a title with accessible options to make the program for everyone, including those with a print disability, but they also acknowledged that the sometimes limited availability of accessible titles makes it more challenging to settle on an appropriate book.

Ultimately, the team established the following criteria:

- Must be written by a living author

- Must be able to generate discussion and exchange of ideas

- Must be appealing to a broad range of readers of varying ages, literacy levels, and life experience

- Must be in print and available for purchase in paperback, e-book, and audiobook

- Must be strongly written with elements that will generate excitement among readers

- Must be published in the last five years

- Must meet the current year's preselected theme (if there is a preselected theme)

(These selection criteria apply only to the main selection choice. Any read-alike titles or additional books associated with Dal Reads do not have to meet the selection criteria.)

The team decided that it was important to choose a living author so that he or she could potentially take part in readings 


\section{READERS' ADVISORY}

or other events. Some of the selection criteria are there to ensure availability of the book, while other elements of the selection criteria are more subjective and there to ensure that the book is a good fit for a unity reading program by providing ample fodder for discussion and programming ideas.

Because the team wanted to announce the title of the book in April before students scattered for the summer, we thought the fastest way to come to a final title selection by that deadline would be to create a shortlist that could be brought to the larger student body to vote on.

Using the selection criteria, the library school students suggested a list of twelve titles. They were then asked to pick three books from the list and provide a short blurb explaining why they chose the book and how it matched the selection criteria. The votes were tallied and three top contenders were identified. The list of three top titles was shared on the recently resurrected Dal Reads blog and the brand-new Dal Reads Twitter and Facebook accounts, asking for student input on which title they would most like to read. As the social media accounts were quite new and therefore low on followers, the students hosted a pop-up voting event in the Killam Memorial Library, the largest of the five Dalhousie Libraries. Library school students on the Dal Reads team staffed the booth throughout the day and took votes from students on the three titles. We also knew this would be a good opportunity to tell students face-to-face about the program, many who had never heard about it before.

From the vote emerged one clear winner. The winning title had as many votes as the two runners up combined. Mr. Penumbra's 24-Hour Bookstore by first-time published author Robin Sloan was the official Dal Reads selection for 2014, a selection completely chosen by students.

\section{RELAUNCHING THE INITIATIVE}

Then came the challenge of promoting the successful title and getting the book into the hands of students. Copies were stocked at two campus book stores, and each Dalhousie Library received copies. One challenge of integrating fiction books into academic libraries is that they don't really fit with the rest of the collection. How can you make a novel about technology, cryptography, and conspiracy fit into a library that specializes in health sciences or agriculture? In an effort to address this challenge, posters and special book stands were designed to draw attention to the book in each of the five Dalhousie Libraries.

Dal Reads was promoted throughout the summer in the Dalhousie Libraries, university bookstores, and by giving promotional bookmarks and a few giveaway copies of the book to the Student Services team to pass on to first-year students coming to campus for summer orientation events.

Two events were planned for the fall, the first was a book discussion group, which worked the same as a book club meeting. The event happened in the cozy University Club Pub, and despite ample promotion and the promise of free food, turnout at the event was disappointingly low.

The second event of the relaunched Dal Reads program was an event with the author, Robin Sloan. Because he is based in San Francisco, we could not afford to fly him to Halifax to join us in person, but he graciously agreed to a Skypebased author chat. Bandwidth issues discovered at the last minute made our Skype chat impossible, but the ever-flexible Robin Sloan agreed to do a text-based Gmail chat, which I moderated. Turnout at this event was somewhat better than the book discussion group, although the majority of people in the room were staff or faculty. Robin Sloan's personality shone through the barrier of a text-based chat, and everyone at the event appreciated his candor, humour, and charm.

\section{MOVING FORWARD}

Now that the first year of the relaunched Dal Reads program is behind us, it is time to reflect on the program. Despite our best efforts, student participation is still low. Our next steps include reaching out to other institutions with unity reading programs to find out what has worked for them to see if we can apply those principles at Dalhousie and searching through the literature for success stories. We know there are students that are looking for a book club experience and an alternative to traditional university recreational opportunities, we just need to find the right way to deliver such an experience to them.

More information about Dal Reads can be found at:

- https://blogs.dal.ca/dalreads

- @dalreads on Twitter

- facebook.com/dalhousiereads 